\title{
Transição tecnológica em uma operadora de plano de saúde: o olhar do usuário
}

\section{| ${ }^{1}$ Aloísio Punhagui Cuginotti |}

Resumo: O setor de saúde suplementar no Brasil vem experimentando, nos últimos anos, novos modelos de atenção à saúde. O presente estudo teve como objetivo caracterizar como os usuários percebem e se posicionam em relação à implantação da Estratégia Saúde da Família (ESF) por uma operadora do tipo autogestão. Utilizandose de grupos focais com usuários considerados "aderidos" e "não-aderidos" à ESF, a pesquisa revela que os usuários têm uma compreensão bastante clara do significado da estratégia, inclusive de seus fortes elementos racionalizadores, percebem as contradições e deficiências no seu processo de formulação e implantação e mantêm um elevado grau de autonomia na escolha dos serviços que lhe sejam mais adequados, muito influenciados pelo tipo de inserção que têm no estabelecimento bancário que mantém a operadora. $\mathrm{O}$ usuário percebe, ainda, o impasse da autogestão entre manter uma ampla rede credenciada de livre acesso ou conseguir avançar no sentido de fazer da ESF o eixo estruturante de sua rede assistencial.

> Palavras-chave: Saúde Suplementar. Operadoras de Planos de Saúde. Transição Tecnológica em Saúde. Estratégia Saúde da Família.

\author{
${ }^{1}$ Médico da Universidade \\ Federal de São Paulo. Mestre \\ em Ciências da Saúde pela \\ UNIFESP. Especialista em \\ Medicina Preventiva pela \\ AMB e Associação Brasileira \\ de Medicina Preventiva e \\ Administração em Saúde; \\ Integrante da Disciplina \\ de Ciências Humanas em \\ Saúde do Departamento \\ de Medicina Preventiva da \\ UNIFESP. Endereço eletrônico: \\ apcuginotti@gmail.com
}

Recebido em: 14/04/2010. Aprovado em: 08/11/2010. 
Algumas operadoras do mercado de saúde suplementar brasileiro, embasadas em novas concepções da gestão do cuidado em saúde que preconizam a otimização da relação entre custo e qualidade, vêm buscando instituir novas formas de assistência ao beneficiário através da construção de desenhos de modelos assistenciais em saúde que se assemelham a ensaios experimentais do que se tem denominado transição tecnológica (MERHY, 2002). Esta almeja um processo de inovação tecnológica através de novas formas da gestão do conhecimento, ou de tecnologias de gestão organizacional, que se traduzem, de um lado, na aplicação de dispositivos que impactem a autonomia da prática médica com a implementação de processos menos dependentes do consumo dos atos médicos e seus corolários (alta utilização dos serviços e incorporação de tecnologias sob a forma de equipamentos) e, de outro, na valorização da produção de tecnologias imateriais, relacionais ou "leves", que caracterizam os processos cuidadores, centrados no usuário e em suas necessidades. Tais estratégias englobam a desospitalização (home-care), os programas de saúde de família, o monitoramento de pacientes de risco à distância, a inclusão de pacientes de risco em case management e disease management, as práticas de prevenção e promoção à saúde, o uso de equipes multiprofissionais, e determinam, em seu conjunto, a construção de um novo paradigma nesse mercado.

Para isso, contam com um robusto aparato de mecanismos de regulação do acesso (ou microrregulação) sobre os prestadores e os usuários, conhecidos como direcionamento, porta de entrada, autorizações prévias, coparticipação, auditorias, pacotes, protocolos, instrumentos de mensuração da performance médica etc., usados em maior ou menor grau pelas diversas operadoras, dos quais o direcionamento de clientela para prestadores preferenciais é o mais importante. Em articulação com os demais dispositivos, este cria o arcabouço para novas formas de produção do cuidado, garantindo a redução da utilização de serviços e dos custos, bem como o aprimoramento da qualidade assistencial, através da otimização da relação entre o custo e a qualidade, ainda que em boa parte dos casos esses processos se pautem pela teoria do risco individual e pela defesa dos processos de segmentação da assistência (MENESES, 2005).

Estudos anteriores deram ênfase às formas de relacionamento que se instituem entre operadoras e prestadores. Isto se justifica pelo fato de a pressão regulatória exercida pelas primeiras recair de forma mais incisiva sobre estes, em função da 
atribuição dos altos custos da assistência à saúde à crescente incorporação de tecnologia médica; da existência de uma legislação atual que coíbe restrições de acesso aos consumidores; da percepção pelas próprias operadoras de que a regulação excessiva do acesso pode gerar mais despesas futuras devido ao agravamento do quadro nosológico do usuário, além da própria inadequação mercadológica de um confronto direto com o consumidor. Daí a necessidade de controle da autonomia dos prestadores e do acompanhamento administrativo sistemático de sua prática, através dos dispositivos microrregulatórios mencionados (CECÍLIO, 2005; MENESES, 2005).

No que diz respeito ao usuário, pode-se dizer que os principais mecanismos de regulação do acesso atuam de forma menos visível, isto é, através de mecanismos mais camuflados ou indiretos, como é o caso do credenciamento de sub-redes de provedores; da segmentação de planos para diferentes faixas etárias; das formas de cálculo atuarial para precificação de produtos que embutem fatores de proteção contra riscos futuros; ou se apresentam mesclados e articulados a outras dimensões, como as práticas cuidadoras e de prevenção e promoção à saúde, reunidas sob a insígnia da Medicina Preventiva.

Tais tecnologias organizacionais integram a já citada "gestão do cuidado", no sentido de instituir uma mudança de paradigma tecnológico que, além de atender às necessidades de controle da sinistralidade, possa também representar uma transição tecnológica na Saúde Suplementar rumo a uma real inovação tecnológica e a uma maior qualidade dos processos assistenciais, tendo, ao menos teoricamente, o usuário e suas necessidades como eixo referencial.

$\mathrm{O}$ artigo apresenta e discute resultados de investigação financiada com recursos do Conselho Nacional de Desenvolvimento Científico e Tecnológico (CNPq) e da Agência Nacional de Saúde Suplementar (ANS), realizada junto a uma operadora (autogestão) que vem trabalhando a implantação de uma "Estratégia Saúde da Família”, com o objetivo de caracterizar a perspectiva dos usuários perante tais mudanças no modo de se organizar a atenção.

\section{Metodologia}

Os estudos sobre satisfação de usuários ganharam destaque na literatura a partir da década de 1970, inscritos no paradigma do consumo de serviços, da cultura de valorização da qualidade e da necessidade de racionalização dos gastos em saúde, 
em que a satisfação do consumidor passa a ser uma meta a ser alcançada pelos serviços. A importância da opinião do usuário para a determinação da qualidade de serviços ou de sistemas de saúde sugere não apenas uma estreita vinculação entre satisfação e efetividade de um programa, como o reconhecimento dos usuários como elementos ativos no processo de produção do cuidado. Tal reconhecimento tem se traduzido em demandas de avaliação e de mensuração da satisfação, o que resultou na proliferação de estudos sobre o tema.

Um problema levantado nesses estudos é a ausência de uma definição generalizadamente aceita de satisfação e de uma teoria de base para orientar a mensuração desse conceito, o que se reflete na adoção de uma grande diversidade de abordagens metodológicas. Os altos níveis de satisfação constantemente encontrados e a variabilidade limitada dos resultados sugerem inconsistência teórico-metodológica e levantam dúvidas acerca da validade do conceito que é medido em tais estudos (STANISZEWSKA; AHMED, 1999).

Os métodos atualmente dominantes de investigação trabalham com a assunção explícita de que o pesquisador sabe o que se quer medir e tem capacidade para realizar tal mensuração. A discrepância entre o modo como os usuários se sentem capazes de dar sua opinião e o veículo como isto é feito faz com que tais estudos possam não apenas ter a ilusão de estar representando a opinião do usuário como podem estar de fato modificando-a (EDWARDS; STANISZEWSKA, 2000). Os resultados também mostram que os pacientes, de forma espontânea, não necessariamente descrevem sua experiência com o cuidado em termos de satisfação ou de insatisfação, sendo portadores de compreensões relevantes e complexas que não se enquadram em expressões simplificadas de satisfação (WILLIANS, 1994). Como o score de satisfação global fornece poucas indicações sobre a experiência do cuidado, muitos desses estudos acabam se restringindo aos indicadores mais óbvios para sua mensuração, resultando que as avaliações de satisfação de usuários se mostrem inaptas em fornecer um modelo teóricoconceitual consistente para contemplar sua complexidade.

Os escassos modelos teóricos explicativos existentes a respeito do tema são provenientes da escola de psicologia social norte-americana e do marketing e expressam a penetração de seus respectivos paradigmas no campo da saúde, entre eles a noção de expectativa e a de usuário-consumidor. Nessa vertente, o 
conceito de satisfação é pouco teorizado, admitindo uma polissemia que esvazia sua dimensão analítica, na medida em que pode ser aplicado indistintamente a diversos aspectos dos serviços, inclusive os não diretamente ligados à produção do cuidado. Assim, a satisfação se restringe a uma abordagem limitada e superficial de variáveis necessárias à obtenção da satisfação do usuário e de sua fidelidade como consumidor, ao invés de desenvolver uma compreensão mais profunda e analítica sobre as experiências individuais em relação aos serviços de saúde. Paralelamente, a noção de expectativa passa a substituir a noção de necessidade, categoria mais correntemente usada no campo da Saúde Coletiva e que expressa a experiência real da interação entre o usuário e os serviços (ESPERIDIÃO; TRAD, 2006).

$\mathrm{O}$ presente estudo teve a intenção de ir além das pesquisas de opinião ou de satisfação do usuário/beneficiário, que quase sempre guardam uma relação de exterioridade frente ao processo de produção do cuidado. Adotou-se a expectativa de que a experiência do usuário, ao invés de representar uma informação adicional ou superposta à qualidade dos serviços, é parte constitutiva tanto do modelo assistencial estudado como da dimensão analítica e operatória do processo de avaliação. A abordagem do usuário constitui, assim, um movimento inicial de incursão exploratória que pode interrogar a composição e a adequação das tecnologias do trabalho atualmente vigentes na Saúde Suplementar, não obrigatoriamente expressas por indicadores de satisfação, mas de modo a instituílo como balizador desses processos.Tal opção metodológica implica um esforço, portanto, de se avançar além da avaliação funcionalista, feita de forma isolada ou simultânea, de estrutura, processo e resultados, tal como tem sido pensado a partir dos estudos de Donabedian (1980; 1990).

Em vista da complexidade do tema e de seu referencial teórico, a pesquisa assumiu um caráter qualitativo, na forma de estudo de caso. Este constitui uma estratégia na qual o pesquisador decide trabalhar sobre uma unidade de análise e, nela, faz a observação do caso no seu interior. $\mathrm{O}$ potencial explicativo desta estratégia provém da coerência da estrutura das relaçôes entre os componentes do caso e da coerência das variações dessas relações no tempo, decorrendo da profundidade da análise do caso e não do número de unidades de análise estudadas (CONTANDRIOPOLOUS et al., 1994; DENIS; CHAMPAGNE, 1990).

Outros autores consideram-no um meio de organizar os dados sociais preservando o caráter unitário do objeto estudado, consistindo numa abordagem 
que considera qualquer unidade social como um todo, ainda que não seja possível apreender o objeto em sua unicidade. A adequação dos dados é conduzida e conferida pelo próprio problema que norteia a pesquisa. Consequentemente, este método não é considerado capaz de captar o único, mas afigura-se como uma tentativa de manter juntas, como uma unidade, as características marcantes e importantes para o problema sob investigação (GOODE; HATT, 1972).

A validade interna desses estudos depende, por um lado, da qualidade e da complexidade da articulação teórica subjacente ao estudo e, por outro, da adequação entre o modo de análise escolhido e o modelo teórico. Quanto à validade externa, mais do que uma generalização estatística, os estudos de caso visam a uma generalização analítica, baseada no confronto da configuração empírica de vários casos similares ou mesmo na facilidade com que se pode transferir ou reproduzir um determinado programa em outros meios (CONTANDRIOPOLOUS et al., 1994).

O estudo foi realizado no município de São Paulo, entre 2007 e 2008, em uma operadora de autogestão (OAG) ligada a um estabelecimento bancário. A "baixa adesão dos trabalhadores à Estratégia Saúde da Família”, como reconhecido por sua direção, deu a direcionalidade do estudo, por nos parecer uma boa indicação do posicionamento dos beneficiários diante de uma nova estratégia de cuidado. A pesquisa foi desenvolvida em três etapas. Na primeira, foram escutados os dirigentes da operadora, para caracterizar a formulação oficial da proposta da denominada "Estratégia Saúde da Família" (ESF). Na segunda, foram escutados, com técnicas de entrevista e grupo focal, os membros de uma equipe de um dos módulos da ESF. Por fim, na última etapa, foram escutados, utilizando-se a técnica de grupos focais, os beneficiários da operadora considerados "aderidos" e "não-aderidos" à ESF, bem como o "Conselho de usuários" da operadora. Compôs-se, assim, um "triângulo de observação" (diretoria, equipes nos serviços e usuários), visando a dar maior consistência na fase de análise dos dados.

O projeto de pesquisa foi aprovado pelo Comitê de Ética da Universidade Federal de São Paulo e teve a autorização da direção nacional da operadora. Todos os participantes assinaram Termo de Consentimento Livre e Esclarecido. Os resultados da pesquisa geraram detalhado relatório, apresentado e discutido com os dirigentes da operadora. 
Os usuários da OAG: as diferentes pertenças à empresa condicionam olhares diferentes sobre as mudanças no modelo organizacional

A operadora estudada passou por importantes transformações a partir da década de 1990, que resultaram em diferentes formas de pertença dos funcionários na empresa, consequência, entre outras coisas, da mudança do plano de cargos e salários e do estabelecimento de um piso salarial de ingresso para os novos funcionários bem inferior ao que historicamente vinha sendo mantido.

O resultado desse processo foi a estratificação dos usuários em três categorias: funcionários mais antigos da patrocinadora, que conseguiram manter as prerrogativas salariais e de aposentadoria anteriores a 1998 e que, por terem contribuído ou ainda contribuírem com uma taxa maior para o financiamento do sistema, reivindicam a mesma qualidade dos serviços de saúde a que já estavam habituados (rede credenciada aberta e livre escolha); funcionários da ativa ingressantes antes de 1998 que, apesar de haverem sofrido perdas salariais importantes, ainda valorizam este plano de saúde; e funcionários ingressantes pós-1998, que apresentam perdas salariais drásticas em relação aos funcionários mais antigos, configurando uma nova categoria de usuário aparentemente menos exigente que estes. As consequências diretas do achatamento salarial resultantes da reestruturação da empresa foram, por um lado, a queda de arrecadação global para seu sistema de saúde tradicional e, por outro, a criação de diferentes tipos de trabalhadores, em função da época de ingresso. Desta forma, não há um "usuário típico", "único", padrão, mas uma diversidade de posturas e de doação de sentidos em função das diferentes pertenças à empresa. Esse foi o primeiro achado mais marcante do estudo.

\section{A dimensão conceitual e organizacional da ESF}

\section{Os usuários conhecem a proposta da ESF em seus delineamentos gerais}

Mesmo guardadas suas diferenças de pertença, os usuários mostram boa compreensão da proposta da ESF, nos seus delineamentos mais gerais e conceituais, provavelmente como fruto de um trabalho interno de discussão e de convencimento em torno dessa proposta por parte da operadora. O estudo mostrou uma razoável compreensão dos princípios gerais e da "filosofia" da 
ESF pelos usuários ouvidos, que é tão precisa quanto aquela apresentada pelos técnicos, ao contrário do que supunha a direção. A "falta de conhecimento da proposta" era uma das explicações, por parte dos dirigentes, para a "baixa adesão" à ESF. Chama ainda a atenção a forte convergência de compreensão da proposta em todos os grupos estudados, de modo que, mesmo nos "não-aderidos", há uma boa clareza das diretrizes e, principalmente, das vantagens potenciais da ESF, o que não resulta necessariamente em adesão. É esse fato que convida a ir além do discurso formal, da esfera da cognição, explorando outras possibilidades de explicação para a não-adesão dos usuários.

\section{A concepção organizacional da ESF: indo além da idealidade da proposta}

Ao sair da dimensão puramente discursiva, defrontou-se com novos questionamentos, com posiçôes menos homogêneas, fruto tanto das diferentes pertenças dos usuários escutados como de suas vivências reais com a "materialidade" da ESF, nas transformações no modo de acesso e de cuidado decorrentes da implantação da "Estratégia", em particular o quanto elas possam resultar em maior regulação do uso de serviços e em maior grau de cerceamento do livre-acesso à rede credenciada.

Os usuários apresentam uma boa compreensão a respeito da concepção organizacional da ESF e da coexistência de dois modelos assistenciais polares na operadora, representados pela rede credenciada e pela ESF. A primeira, de livre-acesso via call center, representa o modelo médico tradicional, com forte legitimidade perante os usuários ou beneficiários. Já a ESF é vista como alternativa "potencialmente boa" e mais cuidadora, desde que não ponha em xeque as vantagens da rede credenciada. O usuário, o estudo mostrou, tem uma compreensão bastante clara dos dilemas que a OAG vive nesse momento, em particular o quanto a ESF poderá, ou não, assumir um caráter realmente substitutivo em relação à rede tradicional, passando a funcionar como sua "porta de entrada" e capaz de imprimir uma nova racionalidade ao sistema como um todo.

Os usuários admitem a inevitabilidade da regulação, ou seja, a necessidade da adoção de processos mais "racionalizadores" do uso dos recursos. O quanto e em que grau a ESF vai se transformar em dispositivo para controle do acesso à rede credenciada, historicamente de livre acesso para os usuários, passa a ser elemento 
central na compreensão das resistências à implantação da "Estratégia", inclusive a definição do quanto a ESF assumirá um caráter de estratégia "substitutiva" ou "somativa". Os usuários, mesmo os considerados aderidos, a veem como "somativa", ou algo que se acrescente ao que já se usa, em particular a livreescolha do "seu" médico de família. Caso pressintam qualquer ameaça real de restrição ao livre-acesso, aparecem as críticas e resistências.

A direção da operadora tem clareza de que é vital para a sobrevivência do sistema que a nova modelagem assistencial adotada, além de representar uma qualificação do cuidado, articule-se orgânica e funcionalmente com a rede credenciada, resultando maior aproximação entre as duas lógicas atuais e construindo uma nova lógica de funcionamento. $\mathrm{O}$ estudo mostra a existência de dois sistemas que correm em paralelo, praticamente sem articulação com a grande rede credenciada acessada sem restrição e dissociada da concepção assistencial da ESF, a qual ainda não tem se constituído em uma alternativa viável para reverter a atual lógica de funcionamento daquela.

Ao se referirem à ESF como porta de entrada do sistema, os usuários ainda não identificam isso como uma forma de direcionamento. Apesar de perceberem a relação entre regulação e modelo assistencial, não conseguem apreender ou reconhecer sua mecânica principal, uma vez que não percebem o alcance do propósito racionalizador e direcionador da "Estratégia" ao funcionar como um serviço próprio onde deve ser concentrado o atendimento, controlando a dispersão dos usuários entre os prestadores da rede credenciada.

\section{Os usuários percebem os déficits conceituais e as dificuldades operacionais a partir de suas vivências concretas}

$\mathrm{O}$ estudo mostrou como os usuários apresentam surpreendente clareza sobre a operação real da "Estratégia", inclusive ao apontar as dificuldades vivenciadas, entre as quais destacamos: a) a desconsideração das especificidades locais da cidade de São Paulo para a implantação da ESF, o que se traduz na insuficiência e inadequação da própria rede de recursos em relação à quantidade e à distribuição dos módulos, o que impede que a ESF funcione na sua plenitude; b) a dificuldade de fixação de médicos generalistas na equipe, o que descaracterizaria uma das virtudes mais valorizadas da "Estratégia", o vínculo entre o médico ou a equipe e o usuário, criando, portanto, um paradoxo a ser enfrentado pelo modelo; c) atendimento 
restrito ao horário comercial e o não-atendimento de urgências, o que dificultaria o reconhecimento dos módulos como espaço de acolhimento e resolutividade efetivos; d) a carência de demonstração de resultados concretos (ausência de indicadores seguros de impacto da estratégia), o que é percebido particularmente pelos beneficiários que participam do Conselho dos usuários; e) a centralização das informações no módulo da ESF poderia resultar na exposição do usuário perante a equipe e a própria operadora, e na possibilidade de violação do sigilo médico, em benefício dos interesses de racionalização de custo da operadora, enquanto a rede credenciada garantiria maior preservação do anonimato; f) a imprecisão conceitual da ESF, em particular o conceito de "família" e de "território" adotados e inspirados nas proposiçōes do Programa de Saúde da Família do Ministério da Saúde não contemplam as características dos trabalhadores da empresa; g) os obstáculos de ordem cultural para a credibilidade e o uso da ESF pelos usuários parecem ter um peso considerável no conjunto geral das percepções dos usuários, refletindo a própria tensão existente entre as duas modelagens assistenciais em disputa, isto é, a Estratégia, que representaria a novidade e o risco de perdas e restrições ao acesso e consumo de serviços, e o modelo médico dominante, materializado na rede credenciada, com seu acesso sem restrições; $h$ ) as dúvidas a respeito dos custosbenefícios da ESF, pois uma das críticas mais severas à ESF feita pelos usuários "não-aderidos" é o seu alto custo, considerando-se a capacidade instalada e a contratação de grande número de profissionais para cada unidade. Ao se sobrepor ao custo do modelo tradicional, passa a ter caráter claramente somativo, ao invés de substitutivo (por não eliminar a rede credenciada e pela baixa resolubilidade dos serviços da ESF, que não permite que se abra mão daquela).

\section{A autopercepção dos usuários}

As diferentes formas de pertencimento à história da operadora e do banco patrocinador, além de influenciarem na percepção dos usuários em relação à ESF enquanto forma de reorganização da modelagem assistencial nessa operadora, condicionam também comportamentos e formas de autopercepção do usuário específicos em relação a essa realidade. Isto corresponde ao modo como o usuário vê a si próprio e os outros nesse processo - sua autopercepção no plano individual e coletivo. A própria estratificação dos usuários conforme sua posição histórica na empresa, por eles mesmo descrita, já revela um alto grau de discernimento 
da própria situação e um apuramento dessa autopercepção. Constantemente são apresentadas indicações de como as representações dos trabalhadores devem ser compreendidas e consideradas no processo de transição tecnológica, no caso estudado, a implantação da ESF, pois elas têm ou podem vir a ter um forte peso na maior ou menor adesão dos trabalhadores às mudanças pretendidas.

$\mathrm{O}$ achado mais frequente se refere à visão quase aristocrática que alguns usuários desta OAG têm de si mesmos e do seu modelo tradicional, calcado na rede credenciada, em oposição à ESF, mais assemelhada ao sistema público de atenção, o Sistema Único de Saúde (SUS). Estes se veem como pertencentes a "um estrato social diferenciado", tendo "uma percepção de classe média", o que reforça sua autoestima, em contraposição aos usuários do SUS, com quem não querem ser comparados.

Consideram, assim, o modelo tradicional da operadora como "de primeira classe", enquanto a ESF representaria a "categoria econômica", pois, como no sistema público, funcionaria como porta de entrada para o sistema, enquanto o modelo tradicional (rede credenciada) garante o acesso e a livre escolha dos prestadores mais valorizados do mercado, conferindo status aos usuários desta OAG. Por outro lado, afora o grupo explicitamente não aderido, os usuários pesquisados aparentemente não só defendem o novo modelo assistencial como se esforçam em adotar um posicionamento ético, ideológico e político em relação ao mesmo, pela identificação histórica que têm com a OAG e pela necessidade de preservar condições assistenciais mínimas em um horizonte de incertezas no mercado de saúde suplementar.

\section{A produção de valores e sentidos:}

\section{como os usuários sentem o cuidado recebido}

A absorção do significado da ESF, no plano conceitual e na sua concepção organizativa e operacional, ocorre simultaneamente a um processo de reconstrução de valores e produção de sentidos pelo usuário, ao se colocar como eixo referencial das práticas de saúde. Tal construção de sentidos é perpassada pelas já citadas contingências históricas, que influenciam fortemente a forma como cada usuário sente e percebe sua inserção nesse processo.

A percepção mais profunda e pessoal dos usuários em relação à ESF vem inicialmente mesclada com o reconhecimento dos valores éticos que a acompanham, 
mesmo por parte dos usuários não aderidos. Assim, é reforçada a importância do vínculo e da responsabilização, da autonomia, da prevenção e promoção em saúde, da qualidade de vida e, principalmente, o reconhecimento do usuário como sujeito do processo de produção do cuidado, para o qual todos os recursos tecnológicos devem ser disponibilizados. Emerge ainda de forma recorrente a importância da ética nas práticas de saúde, tanto nas relações entre os diferentes núcleos profissionais como enquanto fundamento da produção do cuidado na ESF.

Nem todos os usuários selecionados, com exceção do grupo dos usuários aderidos, têm experiências reais de contato com o aparato assistencial da ESF, o que quer dizer que boa parte das percepções são ainda mediadas pela racionalidade, guardando relativa exterioridade frente a uma experiência significativa com os serviços de saúde a ela relacionados. Este fato já é por si extremamente revelador da disposição dos mesmos em relação à “Estratégia”. É possível perceber que as manifestações dos usuários no campo subjetivo apresentam uma gradação que se desloca de uma percepção ainda intelectual dos valores da ESF para uma vivência pessoal e orgânica com a mesma.

\section{Sentir-se cuidado como produção de valor de uso real}

No entanto, além da percepção ainda "intelectual” dos valores e da ética que embasam a ESF, é perceptível uma discrepância entre o reconhecimento desses valores e seu uso concreto. Entre reconhecê-la como possuidora de princípios e valores legítimos e adotá-la como opção assistencial preferencial parece haver uma distância considerável.

A estratificação histórica feita pelos próprios usuários certamente continua influenciando a experiência sentida do cuidado em relação à assistência proporcionada pela ESF. A caracterização dos grupos em si mesma, feita pelos próprios usuários, também já diz muito a respeito de como eles percebem subjetivamente o cuidado recebido na ESF.

Sendo um dos principais problemas constatados na pesquisa a não-adesão à ESF, são ainda poucas as manifestações referentes às experiências de cuidado concretamente vividas por esses usuários. Parte delas refere-se à própria operacionalização do modelo e a seus mecanismos de regulação, bem como às dificuldades já mencionadas, que podem ser resumidas na maior ou menor possibilidade de acesso ao sistema, na fixação do profissional médico e no 
atendimento das urgências e emergências. Tais características organizacionais impactam desfavoravelmente o sentir-se cuidado e o vínculo com os profissionais, um valor central da ESF, o que soa como um paradoxo com a idealidade do seu discurso. $\mathrm{O}$ atendimento inadequado às urgências, por exemplo, é um dos fatores que mais tem subtraído legitimidade à proposta.

Por outro lado, é muito relevante o fato de que, deflagrado o contato com o atendimento na "Estratégia", as experiências relatadas são descritas como extremamente positivas. Ultrapassadas as barreiras ao acesso e as resistências iniciais, o usuário que adentra a ESF mostra-se muito satisfeito com o atendimento e com o cuidado recebido, o que propicia a construção e a manutenção do vínculo nesse modelo, bem como o sentimento de pertencimento a uma estrutura que o toma como eixo referencial.

Várias expressōes demonstram experiências positivas com a ESF, que correspondem a valores de uso compartilhados por aqueles que a experimentaram: prevenção e promoção à saúde; a atenção com o "todo" do usuário; a valorização do usuário e de suas necessidades; a sensação de estar sendo bem acolhido e bem cuidado; a ESF como promotora da qualidade de vida; a capacidade de propiciar vínculo e relações de camaradagem; de propiciar responsabilização e autonomia dos usuários; de fortalecer e humanizar a relação usuário-equipe e mesmo de propiciar a vigilância contra eventuais desvios éticos dentro da equipe.

\section{Conclusōes: a transiçãao tecnológica real ou a acuidade do olhar do usuário}

A finalização da prospecção do campo com os usuários permitiu enriquecer e ampliar os achados obtidos com os membros da alta direção e da gerência intermediária, confirmando a idealidade do discurso da ESF enquanto estratégia de transição tecnológica e seu atual distanciamento em relação ao mundo e às necessidades dos usuários.

Os dilemas e os impasses da transição tecnológica observados nesta operadora refletem um processo ainda não consolidado, que podem ser compreendidos não apenas por sua natureza jurídico-empresarial, como pelas transformações históricas vividas com a implantação da atual política da empresa desde a década de 1990. É possível, desde o início, constatar a existência de um campo em completa transformação, com um alto grau de complexidade, que vem 
produzindo uma multiplicidade de usuários, o que se traduz em um espectro amplo de compreensões e percepçôes acerca da transição tecnológica que vem sendo conduzida por esta organização.

A abordagem utilizada possibilitou o encontro de usuários muito diferenciados, tanto do ponto de vista do posicionamento ético-político, como de compreensão da proposta e de apropriação das informações, dando claras indicações do seu protagonismo no que diz respeito à viabilidade ou não da Estratégia Saúde da Família nessa OAG.

O distanciamento entre a idealidade do discurso da ESF e o mundo dos usuários decorre das contradiçõos intrínsecas de sua formulação e operacionalização, bem expressos nos problemas já enumerados, e da coexistência de duas lógicas assistenciais que correm em paralelo e em permanente disputa. Assim, enquanto o modelo assistencial tradicional representado pela rede credenciada continua atuando sem muitas amarras, parece não existir de fato um investimento financeiro mais substancial para tornar a ESF uma alternativa assistencial viável.

É visível também a ambivalência da OAG em relação ao "tudo-pode" e à regulação, entre uma tradição de flexibilidade e generosidade no uso dos recursos e a premente necessidade de sobrevivência em uma economia de mercado, na qual o direcionamento e o controle de custos são vitais.

Os achados do estudo podem ser reordenados em quatro focos que possibilitam uma visão mais abrangente do caso:

1) A percepção do usuário sobre a dupla face do processo de regulação e transição tecnológica: o estudo mostrou como os usuários têm uma compreensão acerca dessa relação constitutiva da transição tecnológica - regulação/modelo assistencial - bastante diferenciada em função de sua pertença na empresa. Mesmo os usuários aderidos, em seu discurso aparentemente favorável à ESF, confirmam seu papel de regulação, ainda que pela denegação, procurando compreendê-la pelo prisma da gestão do cuidado. Ou seja, o reconhecimento existe, o que varia é a atribuição de valores a respeito, alguns dando uma conotação de cerceamento à rede credenciada e outros a compreendendo como um controle necessário à saúde do usuário e da empresa.

2) O alcance da ESF como estratégia de transição tecnológica: há indicações de que a transição tecnológica que vem sendo conduzida por essa OAG, nos 
moldes em que tem sido feita até agora, não aponta para uma tendência à substitutividade em relação ao modelo médico-hegemônico, pautandose até agora por seu caráter somativo. Isso pode ser observado pela própria convivência das duas lógicas assistenciais, já que a maior parte dos usuários ainda utiliza intensamente a rede credenciada, mesmo os declaradamente aderidos à ESF. A escuta dos usuários forneceu importantes elementos para questionar a viabilidade da transição tecnológica através da ESF nesta OAG. Não sendo possível eliminar totalmente a rede credenciada, o custo da ESF, com suas características atuais, sempre se somará ao custo daquela, a menos que ocorra um redirecionamento das diretrizes organizacionais visando a um investimento financeiro mais significativo na ESF para esvaziar o valor tradicionalmente atribuído ao modelo tradicional. $\mathrm{O}$ argumento utilizado pelos usuários não-aderidos, de que a nova proposta pode ser satisfatória para os usuários mais jovens ou que ingressaram mais recentemente no banco patrocinador ou na operadora (em que a qualidade oferecida pela ESF estaria em conformidade com a menor taxa de contribuição para o financiamento do sistema oriunda dos salários mais baixos), acentua ainda mais a natureza somativa da ESF, pois atesta que eles não cogitam em hipótese alguma a possibilidade de abrir mão da rede credenciada tradicional.

3) O impacto da ESF na micropolítica do processo de trabalho: os achados deste estudo não permitem afirmar se a coordenação do cuidado pela ESF, ainda baseada na microrregulação, tem trazido mudanças significativas no processo de trabalho, na produção do cuidado e na composição tecnológica nesta OAG. As manifestações positivas a respeito de transformações na micropolítica do processo de trabalho ainda não acenam para mudanças nas relações interprofissionais, mantendo-se a dinâmica tradicional dos diferentes núcleos profissionais, com a conhecida divisão rígida de papéis entre os diferentes atores. Em relação à construção de vínculo, as declarações dos usuários parecem mostrar que este ainda predomina com o profissional médico. A valorização da equipe, ainda que presente, ainda é periférica na maior parte das falas. Tampouco há indicações de modificações na composição das equipes, de um redesenho das relações dentro das mesmas, bem como na distribuição de tarefas. 
4) Possibilidades de maior qualificação da produção do cuidado: a operadora não dispõe de dados que demonstrem maior qualificação do cuidado promovido pela ESF. É admitida a inexistência de dados qualitativos e quantitativos que demonstrem a redução da fragmentação do cuidado, o aumento da responsabilização, bem como o impacto sobre indicadores clássicos, sobre a utilização da rede credenciada ou sobre o consumo de procedimentos. Esse problema é ainda agravado pela baixa adesão à "Estratégia".

Os depoimentos dos usuários também deixam poucas evidências de que tenha havido um aprimoramento da qualificação da assistência ou que se tenha alcançado algum efetivo papel microrregulatório da ESF, sobretudo seu papel de funcionar como porta de entrada do sistema, o que é admitido direta ou indiretamente por vários usuários. Por outro lado, é possível afirmar que, onde foi possível a construção de vínculo, os resultados concretos do cuidado foram mais promissores, mesmo que para um grupo restrito de usuários, como é o caso do grupo de vivência da terceira idade que participou de um dos grupos focais.

Observa-se que, embora a transição tecnológica através da ESF seja decisão política da operadora (ainda que não isenta de conflitos e dúvidas quanto à sua efetividade), ainda apresenta baixo "valor de uso" para os usuários, o que se expressa na baixa adesão ao programa e às atividades de promoçãa e prevenção. Incrementar o valor de uso dos diferentes formatos de transição tecnológica pode ser um desafio não trivial.

Posto tudo isso, operar um remanejamento e um redirecionamento da lógica assistencial que se aproxime da vida de cada usuário continua sendo uma aposta, que parece repelir qualquer fórmula de resultados rápidos e de custos baixos. Os usuários parecem querer dizer nesta pesquisa que uma transição tecnológica que venha ao encontro de suas necessidades e seja realmente efetiva, sob qualquer formato que se apresente, requer mobilização de recursos financeiros, capacidade organizacional, flexibilidade, sensibilidade e tempo.

Se apreender a percepção dos usuários era inicialmente visto como um desafio, ao final da pesquisa é possível confirmar que não se pode ter a pretensão de captá-la em sua totalidade, o que anima a construção de novos referenciais e novos desenhos metodológicos. 


\section{Referências}

CECÍLIO, L.C.O. (Org). Duas faces da mesma moeda: microrregulação e modelos assistenciais na saúde suplementar. Rio de Janeiro: ANS, 2005, 270p. (Série A. Normas e Manuais Técnicos - Regulação e Saúde 4).

CONTANDRIOPOULUS, A-P. et al. Saber preparar uma pesquisa: definição, estrutura, financiamento. Tradução Silvia Ribeiro de Souza. São Paulo: Hucitec, 1994. 215p.

DENIS, J-L.; CHAMPAGNE, F. Análise da implantação. Revisão: Zulmira Maria de Araújo Hartz e Luiz Cláudio S. Thuller. In: HARTZ, Z.M.A. (Org). Avaliação em SAÚDE: dos modelos conceituais à prática na análise da implantação de programas. $1^{a}$ reimpressão revista. Rio de Janeiro: Fiocruz, 2000. p. 49-88.

DONABEDIAN, A. Explorations in quality assessment and monitoring V. 1. The definition of quality and approaches to its assessment. Ann Arbor, MI: Health Administration Press, 1980. DONABEDIAN, A. The seven pillars of quality. Arch Pathol Lab Med, v. 114, p. 1115-8, 1990. EDWARDS, C.; STANISZEWSKA, S. Accessing the user's perspective. Health and Social Care in the Community, v. 8, n. 6, p. 417-424, 2000.

ESPERIDIĀO, M.A.; TRAD, L.A.B. Avaliação de satisfação de usuários: considerações teórico-conceituais. Cad. Saúde Pública, Rio de Janeiro, v. 22, n. 6, p. 1267-76, 2006. Disponível em <http://www.scielo.br/pdf/csp/v22n6/16.pdf>. Acesso em: 25 set. 2006.

GOODE, W.J.; HATT, P.K. Métodos em pesquisa social. Trad. Carolina Martuscelli Bori. 4a ed. São Paulo: Nacional, 1972. 488p.

MENESES, C.S. Mercado de saúde no Brasil, qualificação assistencial e transição tecnológica: um desafio regulatório para o Estado. 2005. 379p. Tese (Doutorado em Saúde Coletiva) - Faculdade de Ciências Médicas, Universidade Estadual de Campinas, Campinas, 2005. MERHY, E.E. Saúde: a cartografia do trabalho vivo. São Paulo: Hucitec, 2002. 189p. STANISZEWSKA, S.; AHMED, L. The concepts of expectation and satisfaction: do they capture the way patients evaluate their care? J. Adv. Nur., v. 9, n. 2, p.364-372, 1999.

WILLIANS, B. Patient satisfaction: a valid concept? Soc. Sci. Med., v. 38, n. 4, p.509-516, 1994. 


\section{Abstract}

\section{Technological transition in a supplemental health care provider: the user's viewpoint} The Brazilian supplemental health care sector has been experiencing new health care models in the last few years. This paper aims at featuring how users perceive and how they express themselves in relation to the deployment of a program known as Family Health Strategy (FHS) by a self-management health care provider. Through focal groups, the research reveals that users present a rather clear view on the meaning of strategy, including its remarkable rationalizing elements. In addition, they percept contradictions as well as deficiencies in the formulation and deployment process, and they keep a high level of autonomy in the choice for more adequate services, which are greatly influenced by the type of insertion that they exert in the bank institution that maintains the health care service provider. Users also perceive the predicament presented by self-management regarding the maintenance of a broad authorized free access network and the advance towards turning FHS into the structuring backbone of its assistance network.

> Key words: Supplemental Health Care. Self-Management Service Provider. Technological Transition in Health. Family Health Strategy. 